\title{
Current Understanding of Post-thyroidectomy Hypocalcaemia
}

\author{
Onkar Rathod, M.Sc. ', S.R. Masoodi, D.M. ${ }^{2}$ \\ 'Medical SRV, Meyer Organics Pvt. Ltd. ²Professor, Department of Endocrinology, SKIMS, Srinagar
}

\section{A B S T R A C T}

\begin{abstract}
Background: The reported incidence of transient hypocalcaemia ranges from $0.3 \%$ to $49 \%$, and that of permanent hypocalcaemia ranges from $0 \%$ to $13 \%$ depending of cutoff used. Decline in serum calcium or intact parathyroid hormone (iPTH) levels after surgery have been suggested as being reliable predictors of postoperative hypocalcaemia. Although these determinants are reliable, it is not always easy to predict status of the patient to decide their discharge or need of supplementation

Methods: we have searched for clinical studies in Pub Med on 31/01/2012: with a keyword post Thyroidectomy 'Hypocalcaemia'. The first inclusion criteria were studies published in year 2002 and 2012.Further we included: Original research; studies Thyroidectomy (total or partial). Also, we narrowed our inclusion with the words: Hypocalcaemia; calcium supplementation alone or in combination; Post-thyroidectomy hypoparathyroidism.

Results: of 149 articles searched demonstrated the heterogeneous nature of symptomatic and biochemical hypocalcaemia because different studies used different cutoffs, some studies have expressed concern regarding the routine use of prophylactic calcium after surgery because a large number of patients are treated unnecessarily. However number of studies showed routine calcium supplementation for patients undergoing total or completion thyroidectomy is safe and inexpensive.

Conclusions: Hypoparathyroidism after thyroidectomy remains the most widely accepted cause of hypocalcaemia. Prophylactic treatment of hypocalcaemia with vitamin D or metabolites + calcium or calcium alone is a cost-effective strategy. JMS 2013; 16(2):75-79

Keywords: Hypocalcaemia, Hypoparathyroidism, Thyroidectomy, Postoperative complications
\end{abstract}

\section{INTRODUCTION}

Hypoparathyroidism is a well-recognized complication of thyroid and parathyroid surgery. Transient hypoparathyroidism occurs in $10 \%$ of patients who undergo total thyroidectomy ${ }^{1}$. Postsurgical hypocalcaemia resulting from inadequate parathyroid hormone (PTH) secretion could cause neurologic complications and respiratory compromise. ${ }^{2}$ A multidisciplinary approach involving an endocrinologist and surgeon is imperative to reduce the morbidity. New drugs currently in clinical trials offer promising treatment options.

Supplements with Calcium and vitamin D or its analogues is standard and effectively treat hypocalcaemia associated with postsurgical hypoparathyroidism. Postsurgical measurement of PTH allows early identification of patients likely to require supplement therapy which prevents

\section{Correspondence}

Onkar Rathod, M.Sc. (Clinical Research),

303, Kulswamini Residency, Kharghar Sec 13,

Navi Mumbai - 410210

E-mail: onkarrathod@gmail.com hypocalcaemia-related complications and allows early discharge. Permanent hypoparathyroidism should receive appropriate follow-up care to monitor for long-term complications related to supplemental therapy ${ }^{3}$.

Patients with hypocalcaemia symptoms, a low parathyroid hormone (PTH) level $(<3 \mathrm{pg} / \mathrm{ml})$, or a low serum calcium level following a thyroidectomy require calcium supplementation ${ }^{4}$. However, which patients should receive calcium supplementation is always a topic of debate in present review we will discuss current understanding about post thyroidectomy hypocalcaemia and its management.

\section{Magnitude of the problem}

Hypocalcaemia after total thyroidectomy is reported to occur in 0.33 to $65 \%$ of patients ${ }^{4}$. Variations in surgical expertise and the exact nature of the procedure, this wide disparity can be further explained by the variety of laboratory ranges for normocalcemia and the lack of a widespread and consistent definition of hypocalcaemia. Of the articles reviewed the reported rate of transient hypoparathyroidism ranged from 5 to $71 \%$. The rate of 
permanent hypoparathyroidism ranges from 0 to $3.5 \%$.Definitions of transient hypoparathyroidism included: postoperative hypocalcaemia that resolved in less than 6 months, requirement for calcium/vitamin D supplementation complete resolution occurred within 6 months, need for calcium/vitamin D supplementation less than twelve months. Definitions of permanent hypoparathyroidism included: hypocalcaemia 6 months after surgery, no evidence of recovery within 6 months, calcium less than $8.5 \mathrm{mg} / \mathrm{dl}$ without calcium supplements at one year.

Mitra I et al demonstrated in his 127 patients who underwent thyroidectomy without neck dissection, overall 68 patients (23\%) had transient postoperative hypocalcaemia. Total combined with central neck dissection for the treatment of differentiated thyroid carcinoma is more likely to result in transient $(51 \%)$ and permanent $(12 \%)$ hypocalcaemia. Author concluded that, elective neck dissection should be performed selectively, with a high expectation of postoperative hypocalcaemia. ${ }^{5}$

The incidence of temporary hypoparathyroidism (due to damage, de-vascularization or injury to parathyroid gland) ranges from 1.6 to $50 \%$ across centers. To protect against symptomatic hypocalcaemia after a thyroidectomy, many surgeons routinely discharge patients from the hospital but continue to treat them with calcium supplementation and/or calcitriol, the hormonally active form of vitamin D3.

\section{Levels of Serum Calcium \& iPTH to define post thyroidectomy hypocalcaemia}

There is no consensus apparent on literature review as to what constitutes post-thyroidectomy hypocalcaemia and hypoparathyroidism. To review definitions and protocols in studies predicting postoperative hypocalcaemia a PubMed literature search was performed using the key words "total thyroidectomy", "hypocalcaemia. In the studies that defined hypocalcaemia, majority were based on definition on biochemical parameters alone also some studies included both biochemical parameters and clinical symptoms The biochemical definitions of hypocalcaemia $(\mathrm{mg} / \mathrm{dl})$ included: Ionized calcium values less than $3.8 \mathrm{mg} / \mathrm{dl}$, to less than $4.68 \mathrm{mg} / \mathrm{dl}$, corrected or total calcium values less than $7.2 \mathrm{mg} / \mathrm{dl}$, to less than $8.48 \mathrm{mg} / \mathrm{dll}$. $^{7,8}$ Most studies used serum calcium of less than $<8 \mathrm{mg} / \mathrm{dl}$. This literature review confirms that even today there is no consistent use of rationale for, or seeming need to declare definitions of 'clinical' or 'biochemical' hypocalcaemia when reporting outcomes of total thyroidectomy.

\section{Timing of determining serum calcium \& iPTH levels}

It was found that the greatest decrease in post-operative serum calcium levels, compared to pre-operative levels, occurred on the morning of the first post-operative day ${ }^{12-18}$ hours after the operation).Therefore it is recommended to measure post-operative serum calcium $(\mathrm{mg} / \mathrm{dl})$ on morning of first post-operative day. ${ }^{9}$ There is considerable controversy concerning which measurements to perform and when to predict transient or permanent post- operative hypoparathyroidism. Some Authors recommend intraoperative and peri-operative iPTH monitoring ${ }^{10,11}$. Asari et al. measured iPTH levels, 24 hours after total thyroidectomy, and calcium levels, on the second postoperative day, and found that with these measurements it was possible to predict hypoparathyroidism with high sensitivity, specificity and positive predictive value ${ }^{12}$. However, in another study, no significant correlation was found between PTH levels 24 hours after surgery and the development of significant hypocalcaemia ${ }^{13}$ Yet another study supported the usefulness of iPTH monitoring, but noted that the high cost of monitoring represented a major limitation to clinical use. Serum calcium may be monitored instead of $\mathrm{PTH}^{14}$.

Considerable research in the past decade is done to develop better predictors of hypocalcaemia and management guidelines. Lam et al reported the value of the 1-hour postoperative parathyroid hormone (PTH) level by showing that all patients with a level of $8 \mathrm{ng} / \mathrm{L}$ would develop hypocalcaemia. ${ }^{15}$ The cut-off value of 1 hour PTH $8 \mathrm{ng} / \mathrm{L}$, however, fails to predict eventual hypocalcaemia in the majority of patients. Cote $\mathrm{V}$ et al have proposed a 1-hour PTH cut-off of $15 \mathrm{ng} / \mathrm{L}$ for prophylactic supplementation should allow the prevention of the majority of cases of hypocalcaemia, leading to significant cost savings by shortening hospital stays. ${ }^{16}$

\section{Actual requirements of Calcium and Vitamin D3 supplementation postoperatively}

It has been demonstrated that routine oral vitamin $\mathrm{D}$ or metabolites and calcium prophylactic administration during the postoperative period reduces symptomatic hypocalcaemia rate some experts have expressed concern regarding the routine use of prophylactic calcium after surgery because a large number of patients are treated 
unnecessarily.

Multidisciplinary approach involving an endocrinologist and surgeon is imperative to reduce the morbidity associated with hypoparathyroidism after thyroid and parathyroid surgery. A number of patients who experience immediate post-operative hypoparathyroidism recover parathyroid functions within 6 months of thyroid surgery, and very few patients $(4.4 \%)$ develop permanent hypoparathyroidism (hypoparathyroidism that persists 6 months after surgery. ${ }^{17}$ Low calcium levels before surgery, the failure to identify all parathyroid glands during surgery, and parathyroid auto-transplantation are associated with a higher risk of hypoparathyroidism after thyroidectomy. In addition, extensive surgery and technical difficulties, such as those due to a highly vascularized goiter (eg, in the setting of Graves disease) or bilateral central ligation of the inferior thyroid artery during thyroidectomy, increase the risk of permanent hypoparathyroidism. ${ }^{18,19}$ hypoparathyroidism also include those who undergo surgery for recurrent goiter or extensive lymph node dissection for thyroid cancer.

Treatment for postsurgical hypoparathyroidism is generally recommended for patients who exhibit symptoms of hypocalcaemia or have corrected serum calcium concentrations less than $7.5 \mathrm{mg} / \mathrm{dL}$. Acute hypocalcaemia is treated with either oral calcium or an intravenous infusion of $10 \%$ calcium gluconate (e.g. 2 g over 2 hours). Since a bolus of intravenous calcium gluconate will increase serum calcium for only 2 to 3 hours, a continuous calcium gluconate infusion should be considered in patients with severe hypocalcaemia who are unable to take oral supplements. The rate of infusion should be adjusted on the basis of subsequent calcium levels and monitored every 6 to 8 hours until the corrected serum calcium concentration is greater than $7.5 \mathrm{mg} / \mathrm{dL}$. One ampule of calcium chloride infused over 10 minutes can be used in emergent situations; however, the routine use of calcium chloride is avoided because it requires continuous cardiac monitoring. Oral supplementation is started with elemental calcium (1-2 g 3 times daily) and calcitriol ( $0.25-1 \mathrm{mcg} 2$ or 3 times daily) for immediate management of postsurgical hypoparathyroidism. In patients at risk of severe and/or prolonged hypocalcaemia, elemental calcium is started at a dosage of $2 \mathrm{~g} 3$ times daily and calcitriol at a dosage of 0.5 mcg 3 times daily. Intravenous calcium supplementation may be given for 1 to 3 days to minimize symptoms and maintain calcium concentrations between 8 and $8.5 \mathrm{mg} / \mathrm{dL}$ until oral therapy is effective. Serum calcium is monitored frequently depending on the severity of hypocalcaemia and the patient's symptoms. Vitamin D deficiency and hypomagnesaemia are commonly seen in patients with postsurgical hypoparathyroidism. Sanabria A et al in metaanalysis of four studies with 706 patients and concluded that The prophylactic treatment with vitamin D or metabolites + calcium is effective to decrease the incidence of symptoms of temporary hypocalcaemia ${ }^{20}$. The vitamin D level should be normalized with ergocalciferol. Although the recommended ergocalciferol dosage to achieve a $25(\mathrm{OH})$ D concentration greater than $30 \mathrm{ng} / \mathrm{mL}$ is 25000 to 100000 IU weekly for 8 to 12 weeks, it is found that a daily ergocalciferol dosage of 50000 IU can safely be given for 5 days at the beginning of therapy in patients with severe vitamin D deficiency ${ }^{21}$.

Preliminary studies have shown that PTH replacement therapy can be used to maintain normocalcaemia after total thyroidectomy. ${ }^{22}$

\section{Quantity and duration of Calcium supplementation to be administered for prevention or treatment of hypocalcaemia symptoms}

Following hospital discharge, a patient with hypoparathyroidism should be monitored for changes in serum total calcium, phosphorus, magnesium, and albumin levels every 1 to 2 weeks. The frequency of laboratory monitoring should be decreased to every 3 to 6 months once the patient's serum calcium level is in the low-normal range and the patient is receiving stable dosages of calcium and calcitriol In patients with permanent hypoparathyroidism, the goals of therapy are to prevent symptoms of hypocalcaemia and maintain low-normal levels of corrected serum total calcium $(8-8.5 \mathrm{mg} / \mathrm{dL}){ }^{23}$ Because patients with permanent hypoparathyroidism lose the ability to reabsorb calcium through the renal tubular system, they are prone to developing hypercalciuria and renal stones. In these patients, hypercalciuria can be minimized by maintaining a low-normal serum calcium level. Urinary calcium excretion of less than $300 \mathrm{mg} / 24 \mathrm{~h}$. should be maintained with periodic evaluations of 24-hour urinary calcium. If urinary calcium exceeds $250 \mathrm{mg} / 24 \mathrm{~h}$, a thiazide diuretic can be given to reduce urinary calcium excretion and maintain normocalcaemia. Soft-tissue calcification and nephrocalcinosis can be prevented by keeping serum calcium-phosphate product less than 55 . $^{23,24}$ 
Replacement therapy with teriparatide and full-length PTH has also been used to maintain normocalcaemia and reduce calcium and calcitriol dosing requirements in patients with permanent hypoparathyroidism. Teriparatide has also been found to reduce hypercalciuria in patients with permanent hypoparathyroidism. Winer et al evaluated the effects of twice-daily subcutaneous injection of teriparatide in a shortterm study and then for 3 years. ${ }^{25}$ This study reported reduced urinary excretion of calcium in patients with permanent hypoparathyroidism who received teriparatide. Theman et al treated a patient who had hypoparathyroidism due to a calcium-sensing receptor mutation with teriparatide for 13.5 years and noted increased bone mass with no evidence of long-term complications. ${ }^{26}$ Rubin et al investigated full-length PTH injection in 30 hypoparathyroid patients and concluded that the therapy decreased the requirement for concurrent calcium and vitamin D supplementation. $^{27}$

\section{REFERENCES}

1. Kahky M, Weber R. Complications of surgery of the thyroid and parathyroid glands. Surg Clin North Am. 1993;73:307-21.

2. Demeester-Mirkine N, Hooghe L, Van Geertruyden J, deMaertelaer V. Hypocalcaemia after thyroidectomy. Arch. Surg. 1992;127:854

3. Roh JL, Park CI. Intraoperative parathyroid hormone assaymfor management of patients undergoing total thyroidectomy.Head Neck 2006;28:990-7

4. McLeod IK, Arciero C, Noordzij JP, et al. The use of rapid parathyroidhormone assay in predicting postoperative hypocalcaemia after total or completion thyroidectomy. Thyroid 2006;16:259-65.

5. Mitra I, Nichani JR, Yap B, Homer J Effect of central compartment neck dissection on hypocalcaemia incidence after total thyroidectomy for carcinoma $\mathrm{J}$ Laryngol Otol. $2011 ; 125: 497-501$

6. Roderick M, Catherine E, Scott $\mathrm{M}$ et al) Intraoperative parathyroid hormone levels in thyroid surgery are predictive of postoperative hypoparathyroidism and need for vitamin D supplementation. Am J Surg 2005; 189:306-309

7. Serpell JW, Phan D. Safety of total thyroidectomy. ANZJ Surg 2007; 77:1519.

8. Sywak MS, Palazzo FF, Yeh M, et al. Parathyroid hormone assay predicts hypocalcaemia after total thyroidectomy. ANZ J Surg 2007;77:667-670.

9. Hermann M, Ott J, Promberger R, Kober F, Karik M, Freissmuth M. Kinetics of serum parathyroid hormone during and after thyroid surgery. Br J Surg. 2008;95: 1480-1487.

10. Payne RJ, Hier MP, Tamilia M, Mac Namara E, Young J, Black MJ Head Neck. Same-day discharge after total thyroidectomy: the value of 6-hour serum parathyroid hormone and calcium levels.2005; 27:1-7.

11. Lombardi CP, Raffaelli M, Princi P, et al. Early prediction of post thyroidectomy hypocalcaemia by one single iPTH measurement. Surgery 2004;136:1236-41

12. Asari R, Passler C, Kaczirek K, et al. Hypoparathyroidism after total thyroidectomy: a prospective study. Arch Surg 2008;143:132-7.

13. Del Rio P, Arcuri MF, Ferreri G, et al. The utility of serum PTH assessment 24 hours after total thyroidectomy. Otolaryngol Head Neck Surg 2005;32:584-6.

14. Lindblom P, Westerdahl J, Bergenfelz A. Low parathyroid hormone levels after thyroid surgery: a feasible predictor of hypocalcaemia. Surgery 2002;131:515-20.

15. Vanderlei FA, Vieira JG, Hojaij FC, Cervantes O, Kunii IS, Ohe MN, etal parathyroid hormone: an early predictor of symptomatic hypocalcaemia after total thyroidectomy.Arq Bras Endocrinol Metabol. 2012;56(3):168-72.

16. Cote V, Sands N, Hier MP, Black MJ, Tamilia M, MacNamara E, etal Cost savings associated with postthyroidectomy parathyroid hormone levels. Otolaryngol Head Neck Surg. 2008 Feb;138(2):204-8.

17. Bergenfelz A, Jansson S, Kristoffersson A. Complications to thyroid surgery: Results as reported in a database from a multicenter audit comprising 3,660 patients. Langenbecks Arch Surg. 2008;393:667-673

18. Thomusch O, Machens A, Sekulla C, et al. Multivariate analysis of risk factors for postoperative complications in benign goiter surgery: Prospective multicenter study in Germany. World J Surg. 2000;24:1335-1341 
19. Thomusch O, Machens A, Sekulla C,et al. The impact of surgical technique on postoperative hypoparathyroidism in bilateral thyroid surgery: a multivariate analysis of 5846 consecutive patients. Surgery. 2003;133:180-185.

20. Sanabria A, Dominguez LC, Vega V, Osorio C, Duarte D Routine postoperative administration of vitamin D and calcium after total thyroidectomy: a metaanalysis.Int J Surg. 2011;9:46-51

21. Holick MF. Vitamin D deficiency. N Engl J Med. 2007;357:266-281.

22. Rubin MR, Sliney J Jr, McMahon DJ, Silverberg SJ, Bilezikian JP. Therapy of hypoparathyroidism with intact parathyroid hormone. Osteoporos Int. 2010;21:1927-1934.

23. Shoback D. Clinical practice. Hypoparathyroidism. N Engl J Med. 2008;359:391-403
24. National Kidney Foundation. K/DOQI clinical practice guidelines for bone metabolism and disease in chronic kidney disease. Am J Kidney Dis. 2003;42(Suppl 3):S1-201

25. Winer KK, Ko CW, Reynolds JC, et al. Long-term treat $\neg$ ment of hypoparathyroidism: A randomized controlled study comparing parathyroid hormone-(134) versus cal $\neg$ citriol and calcium. J Clin Endocrinol Metab. 2003;88: 4214-4220

26. Theman TA, Collins MT, Dempster DW, et al. PTH(134) replacement therapy in a child with hypoparathyroidism caused by a sporadic calcium receptor mutation. J Bone Miner Res. 2009;24:964973. 